\title{
A Water Recovery System Evolved for Exploration
}

\author{
Mary Jane E. O'Rourke, Jay L. Perry, and Donald L. Carter \\ National Aeronautics and Space Administration
}

\begin{abstract}
A new water recovery system designed towards fulfillment of NASA's Vision for Space Exploration is presented. This water recovery system is an evolution of the current state-of-the-art system. Through novel integration of proven technologies for air and water purification, this system promises to elevate existing technology to higher levels of optimization.
\end{abstract}

The novel aspect of the system is twofold: Volatile organic contaminants will be removed from the cabin air via catalytic oxidation in the vapor phase, prior to their absorption into the aqueous phase, and vapor compression distillation technology will be used to process the condensate and hygiene waste streams in addition to the urine waste stream.

Oxidation kinetics dictate that removal of volatile organic contaminants from the vapor phase is more efficient. Treatment of the various waste streams by VCD will reduce the load on the expendable ion exchange and adsorption media which follow, and on the aqueousphase volatile removal assembly further downstream. Incorporating these advantages will reduce the weight, volume, and power requirements of the system, as well as resupply.

\section{INTRODUCTION}

Fulfillment of the Vision for Space Exploration will require elevation of existing process technologies to higher levels of optimization. The recovery of reusable water from wastewater sources presents the greatest opportunity for large-scale reductions in the logistical burdens for environmental control and life support for crewed space missions, as well as some of the biggest process technology developmental and optimization challenges. Typical resource constraints on weight, power, volume, and resupply tend to drive water recovery process technologies towards highly optimized system solutions, tightly tailored to the expected minimal wastewater contaminant loads envisioned. Conversely, the heterogeneous and highly variable nature of wastewaters generated by humans pushes water recovery process technology needs towards broadacting unit operations, sized with substantial operating margins. These larger operating margins typically come at the expense of the same constrained mission resources. The challenge to water recovery technology and system designers is to achieve the proper balance between these competing forces. Technologies must minimize the dependence on expendable processing elements and limited-life components. At the same time, the technologies must be robust enough to handle unexpected contaminant challenges and process conditions.

NASA's Exploration Life Support (ELS) Program has been developing several water recovery technologies and systems for a number of years. The systems presently being developed fall into two broad categories; biologically-based systems and physiochemically-based systems.

Biologically-based systems center on a bioreactor which uses immobilized microorganisms to break down organic contaminants in the liquid phase. There are several bioreactors in early development phases, with technologies readiness levels (TRLs) between one and three, that are being investigated by the ELS Program. ${ }^{1}$ The biologically-based systems still require physiochemical technologies for pre-processing of wastewater and post-processing of the bioreactor effluent. System architecture varies depending on type of bioreactor and supporting physiochemical technologies used. The primary disadvantage of the biologically-based system is the lack of robustness associated with the use of microorganisms for wastewater treatment.

The Vapor-Phase Catalytic Ammonia Removal (VPCAR) system is an example of a physiochemically-based system, developed at NASA's Ames Research Center. ${ }^{2,3}$ The VPCAR system uses vacuum distillation and catalytic oxidation/reduction to achieve potable water. 
This system is currently being tested at NASA's Marshall Space Flight Center (MSFC). Though this system uses similar unit operations to clean wastewater as the current state-of-the-art, the architecture is significantly different and the technologies used are at lower TRLs.

The current state-of-the-art technology for space-based water recovery and purification is the water recovery system (WRS) which is designed for the International Space Station (ISS). The ISS WRS is appropriately designed for the purpose of providing potable water to the ISS crew; however, for a similar water recovery system to be viably incorporated into the Exploration life support infrastructure, reductions in weight, volume, power, and resupply requirements are necessary.

The design presented herein is for such a nextgeneration WRS, evolved from the baseline ISS water recovery technology, for future Exploration mission applications. This evolved water recovery system (EWRS) incorporates proven process technologies for space-based water and air purification. In the new design, the integration of these existing process technologies is modified from that of the ISS WRS to further optimize treatment of the various waste water streams, contaminant loads, and flow rates. For this reason, a recent habitat study led by NASA MSFC included the EWRS in potential architectures for environmental control and life support (ECLS) systems for lunar-based habitats. ${ }^{4}$ Architectures were defined so as to meet the goal of reducing crew involvement required and resources carried from Earth, and the EWRS promises to achieve this goal.

\section{THE EVOLVED WATER RECOVERY SYSTEM}

The current WRS for ISS uses vacuum distillation, filtration, adsorption, ion exchange, and liquid-phase catalytic oxidation to process humidity condensate, hygiene waste, and urine waste streams to potable water specifications. The current trace contaminant control system (TCCS) is state-of-the-art for spacebased atmosphere quality control. The TCCS employs vapor-phase adsorption and thermal catalytic oxidation to remove the broad spectrum of trace chemical contaminants present in cabin air. The TCCS, with a TRL of nine, is operational onboard the ISS.

A simplified schematic of the baseline ISS architecture is provided in Figure 1. Cabin atmosphere quality control is accomplished by several parallel processes. These include humidity control, carbon dioxide control, and trace contaminant control. Cabin humidity is controlled using a condensing heat exchanger $(\mathrm{CHX})$ where the water vapor is condensed and separated from the process air stream using an inertial separation technique. A portion of the cool, saturated air exiting the $\mathrm{CHX}$ is directed into a zeolite-based carbon dioxide removal process. In parallel to the humidity control and carbon dioxide removal processes, a low flow rate TCCS process employing activated carbon adsorption and thermal catalytic oxidation removes trace contaminants. The exhaust streams from the carbon dioxide removal and TCCS combine and enter the main cabin ventilation duct upstream of the $\mathrm{CHX}$.

On the aqueous side, the condensate collected from the $\mathrm{CHX}$ containing trace contaminants is directed into wastewater storage tanks. Wastewater generated by hygiene activities and the distillate produced by vapor compression distillation (VCD) of the urine waste stream are also directed to the wastewater storage tanks. The combined wastewaters present are fed to the WRS. The WRS employs adsorption and ion exchange beds for primary purification followed by the volatile removal assembly (VRA), a catalytic reactor which removes volatile contaminants from the aqueous phase. The VRA is a two-phase system which requires the addition of gaseous oxygen and operates at elevated temperature and pressure. Upon completion of processing by the VRA, potable water is achieved.

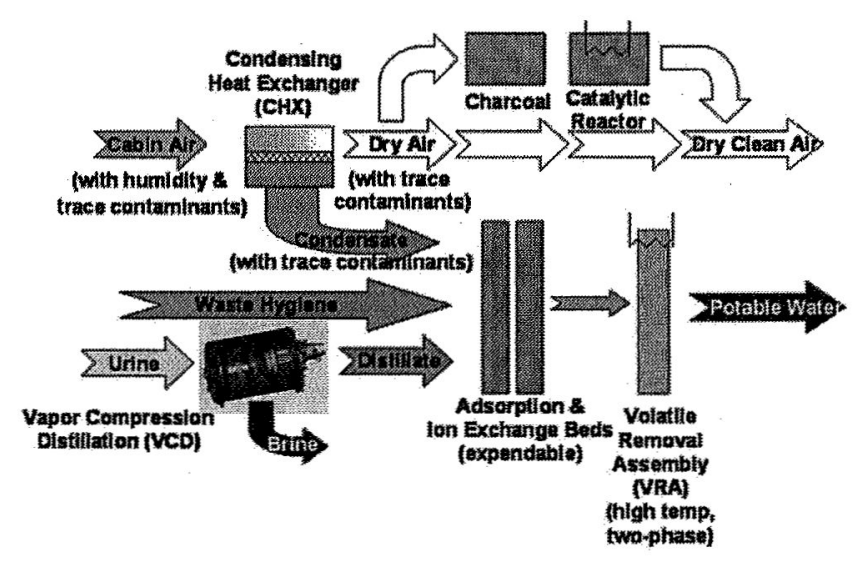

Figure 1. A simplified schematic of the architecture of the baseline WRS for ISS.

A simplified schematic of the EWRS appears in Figure 2, and modifications of system architecture from that of the ISS WRS are apparent. As the first major modification, cabin air is initially fed to a vapor-phase photocatalytic reactor prior to its introduction to the $\mathrm{CHX}$. Volatile organic contaminants are oxidized to carbon dioxide using oxygen available in the air. Hence, volatile organic contaminants in the cabin air are removed at the start of the process, and their carryover into the aqueous phase in the $\mathrm{CHX}$ is minimized. Upon exiting the $\mathrm{CHX}$, resultant dry air is passed over a charcoal bed, as in the ISS WRS configuration; however, the thermal catalytic reactor which follows in the ISS WRS configuration is no longer required to operate at elevated pressure or with the addition of gaseous oxygen. This design change is possible due to the initial processing via the vapor-phase photocatalytic reactor upstream, and consequential reduced contaminant load in the aqueous phase. This 
design change results in a significant increase in the overall simplicity of the WRS, due to the removal of a high pressure gear pump and two-phase separator, with one phase rotary and the other passive.

As the second major modification, humidity condensate exiting the $\mathrm{CHX}$ is processed through VCD rather than fed directly to the expendable absorption and ion exchange beds. The wastewater generated by hygiene

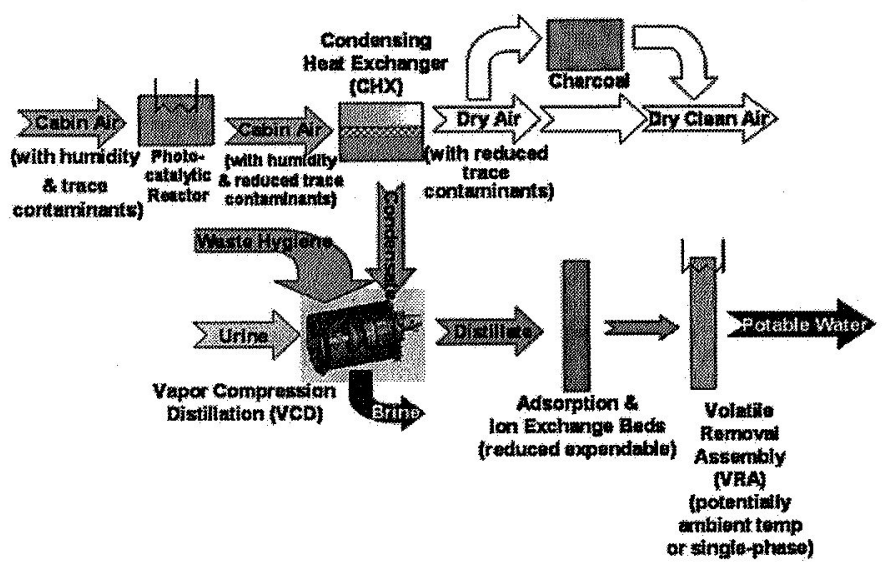

Figure 2. A simplified schematic of the EWRS architecture.

activities is also processed via VCD prior to its introduction to the beds downstream. The urine waste stream continues to be processed as in the ISS configuration. Thus all wastewater streams take advantage of the VCD process. Distillate from the VCD is then passed through the beds and VRA and will exit as potable water.

These major modifications result in several system benefits. By initially introducing cabin air to the vaporphase photocatalytic reactor before feeding it to the $\mathrm{CHX}$, the system is simplified by removal of volatile organic contaminants from the vapor phase rather than from the liquid phase. While in the current state-of-theart system configuration volatile contaminants are absorbed into the aqueous phase upon generation of humidity condensate and removed from this liquid phase, oxidation kinetics dictate that removal of volatile organics from the vapor phase is inherently more efficient. The configuration of the new EWRS exploits this efficiency to reduce system complexity.

Removal of volatile organics from the vapor phase in the EWRS will diminish demands on the aqueous-phase VRA. It is anticipated that the VRA could be operated without the addition of gaseous oxygen and at reduced temperature and pressure. There is also a possibility that the VRA could be completely eliminated, which would result in a dramatic reduction of power and resupply demands beyond those envisioned. The VRA would no longer contribute to oxygen consumption or system mass, and the system would be further simplified by elimination of the phase separation that occurs in the VRA.

The use of VCD technology to treat the condensate and hygiene wastewater streams, in addition to its typical use to treat urine as in the ISS WRS, reduces the resupply penalty of the EWRS as contaminants are concentrated in the VCD brine. Raw condensate and hygiene waste streams are no longer fed directly to the ion exchange and adsorption beds downstream, but are first processed by VCD. This reduces system reliance on these expendable mediae, and a significant reduction in resupply follows.

These modifications, taken together, create a new system architecture which is expected to optimize contaminant removal and improve the overall robustness of the WRS. A conservative comparison between the known requirements of the current state-of-the-art WRS and the estimated anticipated requirements of the EWRS gives a reduction of equipment weight from the known weight of $790 \mathrm{~kg}$ for the ISS WRS to an anticipated weight of $650 \mathrm{~kg}$ for the EWRS. This estimate for the EWRS comes from the expectation that equipment weight will be reduced by the elimination of the pump/separator at the inlet of the water processor, the elimination of the gas removal module downstream of the catalytic reactor, and the reduction in size of the multi-filtration beds.

Resupply will be reduced because the contaminant removal efficiency, defined as grams of contaminant per gram of removal media, is on the order of four times greater with concentration of contaminants in the brine as opposed to use of ion exchange and absorbent mediae. Elimination of the gas removal module downstream of the catalytic reactor will also contribute to the reduction in resupply. Taking these factors into account, resupply is expected to be reduced from the known ISS WRS value of $600 \mathrm{~kg} / \mathrm{yr}$ to an estimated value of $450 \mathrm{~kg} / \mathrm{yr}$ for the EWRS.

Reduction in power will also be accomplished through the previously mentioned elimination of the pump/separator at the inlet of the water processor, as well as the anticipated lower operating temperature of the catalytic reactor. Therefore, time-average power for a six-person crew is expected to be reduced from the know value of $560 \mathrm{~W}$ for the ISS WRS to $500 \mathrm{~W}$ for the EWRS.

These comparisons are made between the known requirements of the ISS WRS and the anticipated requirements of the EWRS, and at the same total inlet flow rate. The VRA is included as a component of the system in the estimation of the requirements of the EWRS. The potential complete elimination of the VRA would further reduce the estimated requirements of the EWRS substantially. Only through generation of test 
data will actual values for the requirement of the EWRS be determined. Test data will also be necessary to determine whether or not a need for the VRA in the EWRS architecture will exist.

While increased VCD throughput does result in increased power to run the VCD phase-change process, it is anticipated that the system architecture will compensate for this by operating the catalytic reactor at a lower temperature of less than $200^{\circ} \mathrm{F}$. The need for the process pump and the mostly liquid separator present in the ISS WRS architecture would be eliminated, thus reducing overall power consumption by the system. VCD is still more efficient than alternate technologies which could serve a similar purpose. In the case that more power is demanded due to the increased VCD throughput, the expectation is that improvement in resupply and reliability will offset this. While power requirements should be minimized as much as possible, the reduction in resupply by concentration of contaminants in the brine as opposed to the multifiltration beds may prove to be even more important. Actual test data need be generated to definitively answer these questions as well.

\section{TECHNOLOGY DEMONSTRATION}

The performance improvement accomplished through this new integration of recovery technologies is anticipated to achieve a more attractive WRS for use in long-term missions for space exploration, as outlined above. Acquisition of the performance data for the EWRS is necessary to meaningfully demonstrate the extent of treatment optimization. The performance assessment is expected to show that the EWRS will provide maximum recovery efficiency from wastewater sources. This assessment will demonstrate the capability of the system to successfully reduce the power and resupply demands of the current state-of-the-art approach.

The proof-of-concept test will be conducted at NASA MSFC, in a specialized testing facility. An existing ISS module simulator will serve to contain the controlled test environment. This module simulator, referred to as the regenerative ECLS module simulator (REMS), has served the same purpose in past ISS WRS testing. This test of the EWRS will primarily utilize existing development hardware.

The test will have two phases. In Phase I of the test, the performance of the new vapor-phase photocatalytic reactor will be established. An atmospheric contaminant load will be generated and collected inside the REMS. Human volunteers will perform exercise and hygiene activities simulating crew activities on-orbit to generate wastewater, adhering to tested protocols developed and fine-tuned for past water recovery tests. Development hardware will thus be challenged with actual wastewater and air contaminant loads. Additionally, a contaminant injection system will introduce volatile contaminants into the REMS atmosphere to more accurately mimic a space-based environment.

Contaminants must be introduced such that they do not condense upon entering the atmosphere. Contaminants must be well-mixed in the REMS atmosphere before introduction to the photocatalytic reactor and TCCS units. Key contaminants and the ranges of their injection rates are listed in Table 2. The atmosphere will be monitored, and injection rates will be modified as needed to adequately represent the desired atmospheric quality.

The number of test participants, test participant activities, and contaminant injection rates are defined so as to closely simulate the atmospheric contaminant load anticipated on an actual mission with a six-person crew. Injection rates and monitoring are also influenced by the appropriate safety review boards. Real-time analysis of the atmospheric contaminant concentrations and the effluent of the photocatalytic reactor will be performed to insure compliance with safety regulations and to provide data needed to assess hardware performance. During the hours in which test participants are not in REMS, a humidifier will run to maintain the environment.

Table 1. Injection-rate ranges of the key contaminants injected into the REMS.

\begin{tabular}{|l|r|}
\hline \multicolumn{1}{|c|}{ Compound } & Injection Rate (mg/h) \\
\hline Methanol & $122.7-244.3$ \\
\hline Ethanol & $3130.6-6227.4$ \\
\hline 2-propanol & $126.8-252.6$ \\
\hline Benzyl alcohol & $12.9-25.3$ \\
\hline 1,2-propanediol & $555.2-1090.3$ \\
\hline Methanal & $21.3-42.5$ \\
\hline Ethanal & $88.7-176.5$ \\
\hline m-/p-dimethylbenzene & $57.3-112.6$ \\
\hline 2-butoxyethoxyethanol & $0.8-1.5$ \\
\hline Dichloromethane & $33.0-64.7$ \\
\hline 2-propanone & $215.9-428.5$ \\
\hline $\begin{array}{l}\text { 4-hydroxy-4-methyl-2- } \\
\text { pentanone }\end{array}$ & $0.1-0.3$ \\
\hline Formic acid & $57.1-112.1$ \\
\hline Acetic acid & $155.8-305.9$ \\
\hline Benzoic acid & $1.9-3.7$ \\
\hline Caprolactam & $6.4-12.5$ \\
\hline Methane & $332.1-704.4$ \\
\hline Carbon monoxide & $88.3-180.0$ \\
\hline Hydrogen & $404.0-813.9$ \\
\hline
\end{tabular}

Operating requirements for the photocatalytic reactor may be modified during this phase to achieve optimum removal of the volatile species from the vapor phase. 
During this phase, the existing TCCS development unit (including activated carbon and catalytic reactor) will be operated nominally. In addition, $\mathrm{CO}_{2}$ will be removed from the atmosphere to maintain concentrations at levels below $1.2 \%$.

Once the operation of the photocatalytic reactor is established, overall performance of the EWRS will be evaluated in Phase II of the test. The primary test objectives are as follows:

- To achieve $94 \%$ water recovery of the combined wastewaters over a 30 -day period.

- To assess distillate quality over the course of the 30day period.

- To assess the ability of catalytic reactor to produce potable water meeting the requirements established in Table 3 while operating at a temperature of $180^{\circ} \mathrm{F}$ and at ambient pressure.

- To assess improvement in product water quality, based on increased reactor temperature of up to $200^{\circ} \mathrm{F}$, if determined to be necessary based on catalytic reactor performance.

- To define any need for intermediate adsorbent and/or ion exchange media upstream from the catalytic reactor, and estimate the expendable resupply requirement, if determined to be necessary based on distillate quality and reactor performance.

- To estimate the expendable rate for the ion exchange bed, if determined to be necessary based on water quality of the catalytic reactor effluent.

Table 2. Quality Requirements for Potable Water.

\begin{tabular}{|c|c|}
\hline Parameter & Specification $^{a}$ \\
\hline \multicolumn{2}{|l|}{ Physical } \\
\hline Total solids & $100 \mathrm{mg} / \mathrm{l}$ \\
\hline Color true & For reference only \\
\hline Taste & For reference only \\
\hline Odor & For reference only \\
\hline Particulates & $40 \mu \mathrm{m}$ (max size) \\
\hline $\mathrm{pH}$ & $4.5-8.5$ \\
\hline Turbidity & 1 NTU \\
\hline Dissolved gas ${ }^{1}$ & (free at $37^{\circ} \mathrm{C}$ ) \\
\hline Free gas $^{1}$ & (STP) \\
\hline \multicolumn{2}{|l|}{ Inorganics } \\
\hline Ammonia & $0.5 \mathrm{mg} / \mathrm{l}$ \\
\hline Arsenic & $0.01 \mathrm{mg} / \mathrm{l}$ \\
\hline Barium & $1.0 \mathrm{mg} / \mathrm{s}$ \\
\hline Cadmium & $0.005 \mathrm{mg} / \mathrm{l}$ \\
\hline Calcium & $30 \mathrm{mg} / \mathrm{l}$ \\
\hline Chlorine (inc. chloride) & $200 \mathrm{mg} / \mathrm{l}$ \\
\hline Chromium & $0.05 \mathrm{mg} / \mathrm{l}$ \\
\hline Copper & $1.0 \mathrm{mg} / \mathrm{l}$ \\
\hline lodine (inc. organic) & $15 \mathrm{mg} / \mathrm{l}$ \\
\hline
\end{tabular}

\begin{tabular}{|l|l|}
\hline Iron & $0.3 \mathrm{mg} /$ \\
\hline Lead & $0.05 \mathrm{mg} /$ \\
\hline Magnesium & $50 \mathrm{mg} / \mathrm{l}$ \\
\hline Manganese & $0.05 \mathrm{mg} / \mathrm{I}$ \\
\hline Mercury & $0.002 \mathrm{mg} / \mathrm{l}$ \\
\hline Nickel & $0.05 \mathrm{mg} / \mathrm{l}$ \\
\hline Nitrate $\left(\mathrm{NO}_{3}\right)$ & $10 \mathrm{mg} / \mathrm{l}$ \\
\hline Potassium & $340 \mathrm{mg} / \mathrm{l}$ \\
\hline Selenium & $0.01 \mathrm{mg} /$ \\
\hline Silver & $0.05 \mathrm{mg} /$ \\
\hline Sulfate & $250 \mathrm{mg} / \mathrm{l}$ \\
\hline Sulfide & $0.05 \mathrm{mg} / \mathrm{l}$ \\
\hline Zinc & $5 \mathrm{mg} /$ \\
\hline
\end{tabular}

\begin{tabular}{|c|c|}
\hline Parameter & Specification $^{a}$ \\
\hline \multicolumn{2}{|l|}{ Bactericide } \\
\hline Residual iodine (min) & $1 \mathrm{mg} / \mathrm{l}$ \\
\hline Residual iodine (max) & $4 \mathrm{mg} / \mathrm{l}$ \\
\hline \multicolumn{2}{|l|}{ Aesthetics } \\
\hline $\mathrm{CO}_{2}$ & $15 \mathrm{mg} / \mathrm{l}$ \\
\hline \multicolumn{2}{|l|}{ Microbial } \\
\hline \multicolumn{2}{|l|}{ Total count: } \\
\hline Bacteria /fungi & $100 \mathrm{CFU} / 100 \mathrm{ml}$ \\
\hline Total coliform & Undetectable \\
\hline Virus & Undetectable \\
\hline \multicolumn{2}{|l|}{ Organic Parameters ${ }^{2}$} \\
\hline Total acids & 500 micro gm/l \\
\hline Cyanide & 200 micro gm/ \\
\hline Volatile organics & $\begin{array}{l}\text { Less than the EPA } \\
\text { MCL per EPA method } \\
524.2 \text {, rev. } 4\end{array}$ \\
\hline Semi-volatile organics & $\begin{array}{l}\text { Less than the EPA } \\
\text { MCL per EPA method } \\
625\end{array}$ \\
\hline Total alcohols & 500 micro gm/ \\
\hline $\begin{array}{lll}\text { Total organic } & \text { carbon } \\
\text { (TOC) } & & \\
\end{array}$ & 500 micro gm/ \\
\hline Uncharacterized TOC $^{3}$ & For reference only \\
\hline \multicolumn{2}{|c|}{$\begin{array}{l}\text { Notes: } \\
\text { a. Maximum contamination level. } \\
\text { 1. No detectable gas using a volumetric gas vs. fluid } \\
\text { measurement system - excludes } \mathrm{CO}_{2} \text { used for } \\
\text { aesthetic purposes. } \\
\text { 2. Each parameter/constituent maximum } \\
\text { contamination level must be considered individually } \\
\text { and independently of others. } \\
\text { 3. Uncharacterized TOC is TOC less the sum of } \\
\text { analyzed organic constituents expressed in } \\
\text { equivalent TOC. }\end{array}$} \\
\hline
\end{tabular}

Operations to generate atmospheric contaminants and wastewater in the REMS during Phase II will proceed as 
established in Phase I. Wastewater generated in the - REMS will be combined with pretreated urine for subsequent processing. Urine will be collected from volunteer donors at a location separate from the REMS. Pretreatment will entail the addition of deionized water, representing flush water, and stabilizer. Pretreated urine will be saturated with air at standard temperature and pressure and free gas will be added to represent an expected quantity. All wastewaters will then be processed via VCD technology and subsequent adsorption and ion exchange beds and the VRA, as outlined.

During operation, the REMS atmosphere and the photocatalytic reactor effluent will be sampled and analyzed via Fourier Transfer infrared analysis and gas chromatography. Water samples will be taken through sample ports at various locations throughout the system and analyzed. Expendables will be monitored and replaced as necessary. A complete inventory of all water within the integrated system will be maintained throughout the test, and a complete record of all expendables will be kept.

At the completion of the test effort, data accumulated will be analyzed to define the performance of the system architecture. Performance of the EWRS will be compared to other technology candidates in development for Exploration missions. It is anticipated that the proposed system will trade favorably against alternate systems in terms of power and resupply requirements and overall system reliability and may therefore supply a foundation for the next generation water recovery system.

\section{CONCLUSION}

The EWRS is a next-generation water recovery system, designed to elevate the existing WRS to the higher level of optimization that fulfillment of the Exploration vision requires. The design for the EWRS is an evolution of that of the current state-of-the-art WRS, which was designed for use aboard the ISS. The new system configuration combines proven technologies for water and atmosphere recovery in a unique integration to optimize treatment of the various waste water streams, contaminant loads and flow rates.

The performance improvement made by modifying the integration of baseline ISS water recovery technologies is anticipated to achieve a more attractive water recovery system for use in long-term space exploration missions. Reductions in reliance on expendable media are expected, in addition to reductions in weight, volume, and power requirements. Overall system robustness will be improved while resupply requirements will be reduced.
A technology demonstration of the EWRS will quantify process optimization. The test will use the same module simulators, protocols, and development hardware as employed in tests of the ISS WRS. Performance data for the EWRS will be acquired, elucidating the extent of the promised increases in system efficiency and laying the foundation for further evolution of WRS technology.

\section{ACKNOWLEDGMENTS}

The authors acknowledge funding for project initiation from NASA's Exploration Systems Mission Directorate. We are also very grateful to the ECLS Test Branch at NASA MSFC for their diligence and camaraderie, with special thanks to Mr. Gene Hartsfield.

\section{REFERENCES}

1. Morse, Audra, et. al., "Biological Treatment of UrineHumidity Condensate Waste Stream", SAE \#200401-2462, Presented at the 34th International Conference on Environmental Systems, Colorado Springs, Colorado, July, 2004.

2. Flynn, Michael T., "The Development of the Vapor Phase Catalytic Ammonia Removal (VPCAR) Engineering Development Unit", SAE \#2004-012495, Presented at the 34th International Conference on Environmental Systems, Colorado Springs, Colorado, July, 2004.

3. Wickham, David, et al., "Results of VPCAR Pilot Scale and System Level Tests for the Selective Oxidation of Ammonia to Nitrogen and Water", SAE \#2005-01-3034, Presented at the 35h International Conference on Environmental Systems, Rome, Italy, July, 2005.

4. Schunk, G., and Roman, M., "Preliminary Sizing and Characterization of an Advanced Environmental Control and Life Support System for a Lunar Habitat", Habitat Structures Study Team, MSFC Technology and Capability Development Project Office, SY10, 2005.

\section{CONTACT}

M. J. E. O'Rourke is currently stationed at NASA's Johnson Space Center in Houston, TX. J. L. Perry and D. L. Carter are stationed at NASA MSFC in Huntsville, $A L$, where this work is on-going.

\section{ACRONYMS}

CHX: Condensing heat exchanger

ECLS: Environmental control and life support

ELS: Exploration Life Support

EWRS: Evolved water recovery system 
ISS: International Space Station

REMS: Regenerative ECLS module simulator

MSFC: Marshall Space Flight Center

NASA: National Aeronautics and Space Administration

TCCS: Trace contaminant control system

TOC: Total organic carbon
TRL: Technology readiness level

VCD: Vapor compression distillation

VPCAR: Vapor Phase Catalytic Ammonia Removal

VRA: Volatile removal assembly

WRS: Water recovery system 